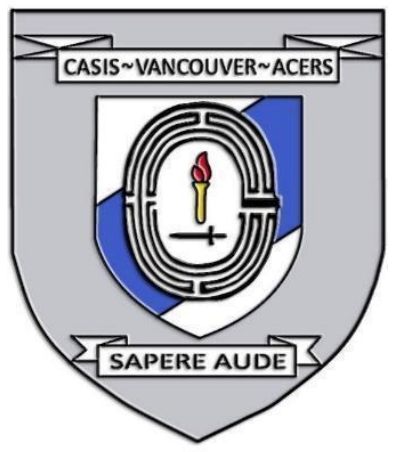

\title{
SPY WATCHING: INTELLIGENCE ACCOUNTABILITY IN THE UNITED STATES
}

Date: November 24, 2020

Disclaimer: This briefing note contains the encapsulation of views presented by the speaker and does not exclusively represent the views of the Canadian Association for Security and Intelligence Studies.

\section{KEY EVENTS}

Dr. Loch K. Johnson presented on intelligence accountability in the United States during the Bush, Obama, and Trump administrations at the 2020 CASIS Vancouver West Coast Security Conference. The presentation was followed by a question and answer period with questions from the audience. The key points discussed were the roles of intelligence in different eras; the usage differences of the various Presidential administrations; and the issues that affected the efficiency and autonomy of intelligence agencies.

\section{NATURE OF DISCUSSION}

\section{Presentation}

Dr. Johnson presented on the roles of intelligence agencies in the United States; the issues that affect intelligence agencies' efficiency and autonomy; and the usage of intelligence agencies by the Bush, Obama, and Trump administrations. Dr. Johnson also presented on the issues encountered by intelligence agencies through each President's administration and methods to improve accountability in the United States.

\section{Question Period}

The question and answer period focused on the global influence US intelligence agencies have had in the past; methods to improve accountability and balance in politics and intelligence; presidential powers and authority; as well as issues that will affect intelligence in the future. 


\section{BACKGROUND}

\section{Presentation}

Intelligence analysts provide government officials with critical information based upon global collections of analysis to facilitate decision making. Technological innovations have provided shields to protect citizens against hostilities and danger across continents but still rely on the human aspect of intelligence. Lawmakers have enacted legislation that provides panels with meaningful authority to conduct intelligence reviews, with the Intelligence Oversight Act of 1980 as the most meaningful intelligence review legislation. This law requires executive grants to report on all significant intelligence activity. Despite this, policy makers have at times ignored or abused intelligence agencies.

The Bush administration overextended the boundaries of authority of the White House over intelligence agencies, undermining the credibility of intelligence organizations and their effectiveness as independent and truly inquisitive agencies. The Bush administration opened the doors to stark executive branch aggression and politicization of spy power and insisted on referencing a debunked CIA allegation that Saddam Hussein had purchased Uranium in a 2002 State of the Union address. A national intelligence escalation in Iraq was never ordered prior to the declaration of war, a standard protocol, and the administration also failed to listen to the department of defence and intelligence agencies. The Bush administration also ignored a 1995 CIA report that aerial threats from terrorism were the number one threat to the United States and had also ignored warnings that Al-Qaeda was the premier threat in 2001. The NSA were also encouraged to unleash SIGINT against the United States citizens and organizations without warrants.

The Obama administration had minimal interest in collaborating with intelligence agencies. The administration resisted in providing access to documents and refused to declassify committee reports during an investigation into the CIA's use of torture against suspected terrorists. The administration then successfully locked away the reports and refused to discuss the topic.

The Trump administration's fast and loose methods with intelligence agencies are unprecedented in the history of US presidents. President Trump refused to be briefed on intelligence matters during the presidential campaign and also rejected receiving important documents once elected to office. President Trump had declared he preferred oral briefings as he did not want to read documents, a critical issue as small details within reports are often important. Mike Pompeo was selected as his CIA director. Pompeo was unqualified as a trustworthy 
factfinder due to his extreme political views and right-wing ideological beliefs. President Trump acted more unilaterally and anti-intelligence than any US president in modern US history and openly expressed his belief that American intelligence agencies were part of the Deep State.

Investments in intelligence innovations and activities can provide precedence. Innovation through technology must also develop alongside relevant laws. The US and Canada will continue to defend their democracies through technological innovations but must be mindful when selecting lawmakers and leaders who understand the capabilities, morals, ethics, and laws surrounding decision making and intelligence agencies. Perhaps the involvement of non-politicians, particularly top intelligence experts, in government roles can mediate the issues.

\section{Question Period}

The idea behind information briefings is to provide information for decision makers to select the best decision. When presidents ignore information, the nation is harmed as a result. Joe Biden has respect for the US Senate and understands what other presidents did not understand. Kamala Harris is an example of the Senate joining the White House, and using the information they have. The current Biden administration will elevate the public understanding of the importance of intelligence agencies in press conferences.

Operational chaos occurs when the CIA spies on anti-war protestors or civil rights activists. A method to mediate this issue is to have an oversight committee. The CIA has no role in the voting issues but merely enforces democratic rights and processes as democracy is fragile. Some countries are completely clueless about what their intelligence agencies can provide.

The US has previously helped overthrow presidents that were democratically elected. Democracies are fragile and require cooperation to help keep them together.

The reputations of American intelligence agencies will improve once citizens understand the important roles these agencies have in environmental issues. Intelligence agents and officers objective and fact-based work may make the agencies more important than the generals and admirals in the room. Intelligence can do many good things and be influential.

Cyber threats are now the premier threat through consensus and will require much work to improve firewalls. This is a pertinent issue for the Biden administration. 
We have recently witnessed more deaths caused by white supremacists than Middle Eastern Jihadists.

Recently, we have also had the COVID-19 pandemic and large amounts of government spending. Hypocrisy had also been a pertinent issue that may be changed when Biden takes office and shares his power. The US constitution must be taken seriously to balance out ambition. Politicians should be educated on intelligence operations through interactions with the CIA and focusing on other countries' use of intelligence and national security practices.

\section{KEY POINTS OF DISCUSSION}

\section{Presentation}

- Intelligence provides information to aid in decision making.

- Despite laws, presidents have abused or ignored intelligence agencies.

- Bush over extended the power of the White House over intelligence agencies.

- Bush had not escalated national security intelligence prior to the declaration of the Iraq War.

- Obama had minimal interest in collaborating with intelligence agencies.

- Trump's fast and loose methods with intelligence agencies were unprecedented.

- Trump acted more unilaterally and anti-intelligence than any other president in modern US history.

- The public must be mindful when selecting lawmakers and leaders who understand the capabilities, ethics, morals, and advantages of using intelligence agencies.

\section{Question Period}

- Ignoring information hurts a nation as a whole.

- Cyber threats are now the premier threat through consensus.

- Recently more deaths have been caused by white supremacists than Middle Eastern Jihadists.

- The US Constitution must be taken seriously to balance out ambition. 


\section{(c) (i) (9)} NonCommercial-NoDerivatives 4.0 International License.

(C) (CASIS Vancouver, 2021)

Published by the Journal of Intelligence, Conflict, and Warfare and Simon Fraser University

Available from: https://jicw.org/ 